\title{
NOTES
}

\section{Metal Dispersion of Bimetallic Catalysts via Stepwise Chemisorption and Surface Titration}

\author{
II. $\mathrm{Ru}-\mathrm{Au} / \mathrm{MgO}$
}

Part I (1) dealt with the application of a stepwise chemisorption and gas titration procedure to a series of $\mathrm{SiO}_{2}$-supported bimetallic $\mathrm{Ru}-\mathrm{Au}$ catalysts. The second part focusses on the application of the same technique to the characterization of a series of $\mathrm{MgO}$-supported $\mathrm{Ru}-\mathrm{Au}$ catalysts. The reason for treating these two catalyst series separately lies in their fundamental differences in terms of morphology and particle size distribution which arises due to the nature of the support strongly influencing the preparative chemistry of the catalysts. While the $\mathrm{SiO}_{2}$-supported series had a bimodal particle size distribution with all the $\mathrm{Ru}$ located in small $(<4 \mathrm{~nm})$ particles, the MgO-supported catalyst series represents a much more complex issue. The two metal components are allocated not only in small particles, but also in medium-size particles (4-15 nm). The major contribution to the total metal surface area comes from these medium-size particles. The surface "adsorption" model proposed for the smill bimetallic particles in the $\mathrm{SiO}_{2}$ series (1) is not adequate to describe the situation in the $\mathrm{MgO}$ series. The hypothesis has been advanced that the medium-size particles might consist of phase-segregated three-dimensional overgrowth structures with one metal deposited on top of the other $(2,3)$. The formation of these medium-size bimetallic particles might be linked to the role of the support during the catalyst preparation. There is evidence from a TPR study carried out on the same catalysts (4) that in the $\mathrm{MgO}$ series $\mathrm{Au}$ gets reduced first while there is a time lag for the reduction of Ru. $\mathrm{Ru}$ particles would, therefore, fall at ran- dom onto either $\mathrm{MgO}$ or already deposited Au particles.

The catalyst pretreatment and the experimental procedure was similar to that described for the $\mathrm{SiO}_{2}$ series (1). The samples used for the chemisorption experiments were taken from a catalyst series that had been extensively characterized in previous work (5-7). Table 1 gives an overview of previous characterization data (5). The catalyst code contains the letter $\mathrm{R}$ for $\mathrm{Ru}, \mathrm{M}$ for the $\mathrm{MgO}$ support, and a three-digit number representing the atomic percentage of $\mathrm{Ru}$ in a given catalyst. The $\mathrm{MgO}$ support (Carlo Erba) had initially a surface area of $15 \mathrm{~m}^{2} / \mathrm{g}$. After catalyst preparation and pretreatment, BET surface areas up to $98 \mathrm{~m}^{2} / \mathrm{g}$ were observed as reported in Table 1. Blank $\mathrm{MgO}$ which had been subjected to similar pretreatment as the $\mathrm{Ru}-\mathrm{Au} / \mathrm{MgO}$ catalysts showed negligible uptake of both hydrogen and oxygen over the temperature range of interest.

Chemisorption of hydrogen at $293 \mathrm{~K}$ and a stoichiometry of $\mathrm{H} / \mathrm{Ru}_{\mathrm{s}}$ equal to 1 was used to determine the dispersion of Ru. The stoichiometry for room-temperature oxygen chemisorption on $\mathrm{Ru}$ is known to depend on the Ru particle size. In the case of small $\mathrm{Ru}$ particles $(<4 \mathrm{~nm})$ an $\mathrm{O} / \mathrm{Ru}_{\mathrm{s}}$ stoichiometry of 2 was found to give average particle size values in good agreement with electron microscopy and $\mathrm{H}_{2}$ chemisorption $(8-17)$. For larger Ru particle sizes $(>8 \mathrm{~nm})$ a stoichiometry of $\mathrm{O} / \mathrm{Ru}_{\mathrm{s}}$ equal to 1 seems to provide a better representative figure for the Ru dispersion (8). As can be seen from Table 2, the average Ru particle sizes derived from $\mathrm{H}_{2}$ chemisorption are 6.3 to 11.6 


\section{TABLE 1}

Catalyst Characterization Data from Previous Work

\begin{tabular}{lcccccc}
\hline Code & $\begin{array}{c}\mathrm{Ru}^{a} \\
(\mathrm{wt \%})\end{array}$ & $\begin{array}{c}\mathrm{Au}^{a} \\
(\mathrm{wt} \%)\end{array}$ & $\mathrm{H} / \mathrm{Ru}^{b}$ & \multicolumn{2}{c}{ WAXS $^{c}$} & $\begin{array}{c}\text { BET arca } \\
\left(\mathrm{m}^{2} / \mathrm{g}\right)\end{array}$ \\
\hline RM089 & 3.48 & 0.81 & 0.079 & 15.5 & 55 & 41 \\
RM064 & 2.12 & 2.34 & 0.100 & $<4.0$ & 26.5 & 98 \\
RM010 & 0.26 & 4.45 & 0.146 & $<4.0$ & 33.5 & 32
\end{tabular}

a Weight percentage of metal as determined by atomic absorption.

${ }^{b}$ As determined by chemisorption at room temperature.

c Averaged metal particle size in nanometers as obtained from WAXS line broadening. Ru particle size is reported as $<4 \mathrm{~nm}$ indicates that no $\mathrm{Ru}$ peak could be detected by WAXS. For Au, the (220) peak was used.

$\mathrm{nm}$, a range where the adsorption stoichiometry for oxygen tends to vary. Therefore, for the determination of the Ru dispersion in the $\mathrm{MgO}$-supported catalysts, more reliance is placed on $\mathrm{H}_{2}$ chemisorption.

Oxygen chemisorption carried out at elevated temperatures led to a dramatic increase in oxygen uptake. Figure 1, for example, shows the oxygen adsorption isotherms on RM064 at three different temperatures. While at room temperature only $\mathrm{Ru}$ is able to chemisorb oxygen, both $\mathrm{Ru}$ and Au chemisorb oxygen at $473 \mathrm{~K}$. However, the observed increase in oxygen uptake cannot solely be ascribed to the onset of chemisorption on the Au surface sites. As already discussed in Part I ( 1 ) it appears

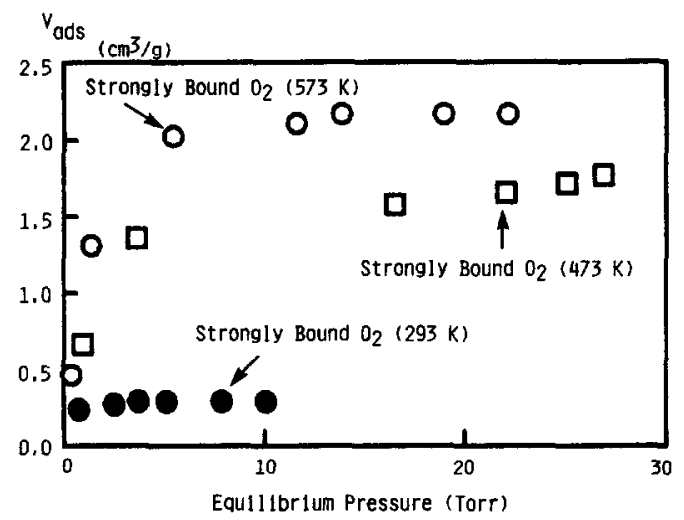

FIG. 1. Oxygen adsorption isotherms for catalyst RM064 at three different temperatures after correcting for reversible uptake of $\mathrm{O}_{2}$ and readsorbed $\mathrm{O}_{2}$. (O) Strongly bound $\mathrm{O}_{2}$ at $573 \mathrm{~K}$; $(\square)$ strongly bound $\mathrm{O}_{2}$ at $473 \mathrm{~K}$; (O) strongly bound $\mathrm{O}_{2}$ at $293 \mathrm{~K}$. that at $473 \mathrm{~K}$ not only surface $\mathrm{Ru}$ atoms, but also subsurface and possibly bulk $\mathrm{Ru}$ atoms participate in the interaction with oxygen. Once again, we take advantage of the fact that only oxygen on Ru sites can be titrated with $\mathrm{H}_{2}$ at $373 \mathrm{~K}$. The difference between the strongly adsorbed oxygen at $473 \mathrm{~K}$ and the titratable oxygen represents the oxygen adsorbed on Au sites.

The gas uptake results are presented in Figs. 2 and 3, and Table 2 summarizes the dispersion and particle size results. Au dispersion and particle size values are derived using a stoichiometry of $\mathrm{Au}_{\mathrm{s}} / \mathrm{O}_{2}$ equal to 4 which gives good agreement with WAXS data on monometallic $\mathrm{Au} / \mathrm{MgO}$. WAXS accounts mainly for the metal present in medium (4-15 nm) and large-size $(>15 \mathrm{~nm})$ particles. Stepwise chemisorption, on the other hand, measures surface metal atoms irrespective of the particle size. Therefore, a comparison of WAXS data with chemisorption data can be quite useful in assessing the relative amount of highly dispersed metal. In the previously discussed $\mathrm{SiO}_{2}$ series (1), the WAXS particle size for Au was in all cases much larger than the corresponding chemisorption particle size. This

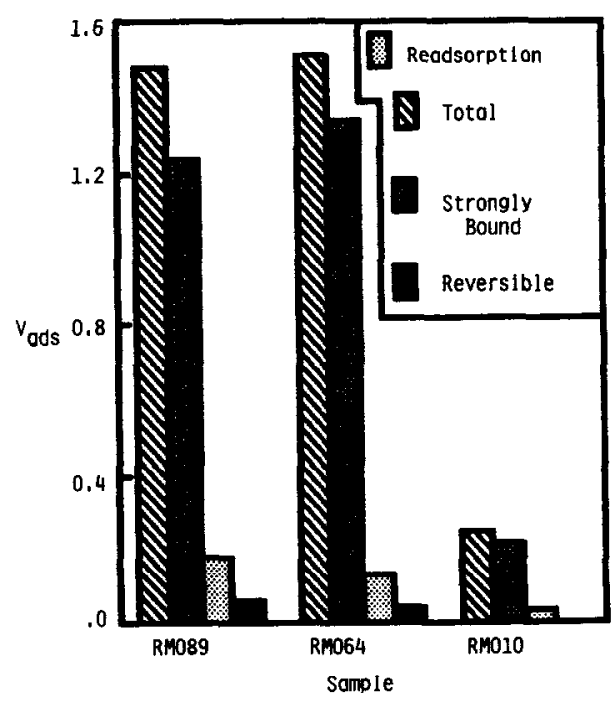

FIG. 2. Bar graph showing summary of oxygen uptake $V_{\text {ADS }}\left[\mathrm{cm}^{3}(\mathrm{STP}) / \mathrm{g}\right]$ at $473 \mathrm{~K}$ on bimetallic catalysts RM089, RM064, and RM010. 


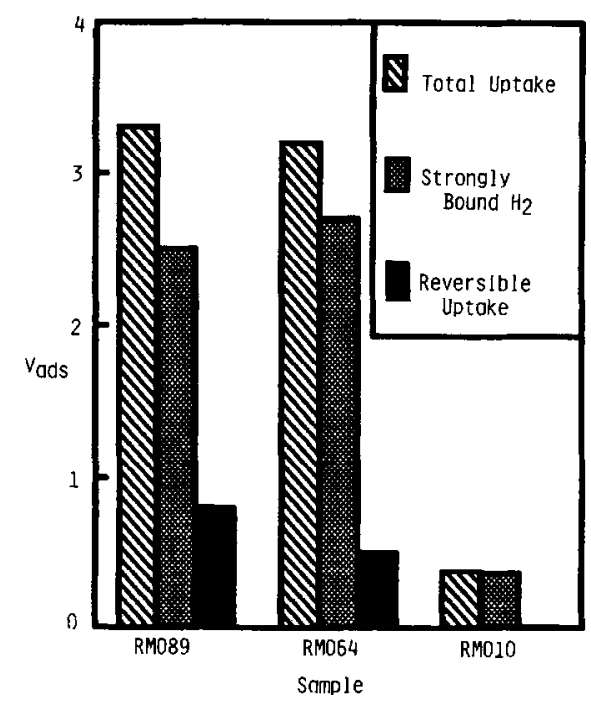

FIG. 3. Bar graph showing summary of hydrogen uptake $V_{\mathrm{ADS}}\left[\mathrm{cm}^{3}(\mathrm{STP}) / \mathrm{g}\right]$ in $\mathrm{H}_{2}-\mathrm{O}_{2}$ titration at $373 \mathrm{~K}$ on bimetallic catalysts RM089, RM064, and RM010.

discrepancy indicated that gold in high dispersion, undetected by WAXS, had to be present (1). From Tables 1 and 2, a comparison of gold particle sizes as derived from WAXS and chemisorption can be made. The fact that the chemisorption data and WAXS data for $\mathrm{Au}$ are in good agreement on catalyst RM089 indicates that in this catalyst not much $\mathrm{Au}$ is present in a state of high dispersion. In catalyst RM064, the Au particle size derived from WAXS is significantly smaller than the Au particle size derived from chemisorption. It should be noted that in this catalyst no WAXS peaks for $\mathrm{Ru}$ were found, despite the fact that according to electron microscopy metal parti- cles (4-15 nm) containing both $\mathrm{Ru}$ and $\mathrm{Au}$ dominated the morphology of this catalyst $(2,3)$. Consequently, the medium-sized bimetallic particles may very well be large $\mathrm{Au}$ particles with smaller Ru particles deposited on top of the gold particles. Thus, part of the Au detected by WAXS would be inaccessible for oxygen chemisorption due to the presence of ruthenium overgrowth structures on top of the gold. This model is in agreement with the XPS observation of ruthenium surface enrichment in the magnesia-supported samples (18). Ruthenium deposited on gold rather than on $\mathrm{MgO}$ would not be subjected to the support interaction with $\mathrm{MgO}$ which is known to suppress the activity compared to unsupported ruthenium powder or $\mathrm{Ru} / \mathrm{SiO}_{2}(2,3)$. Thus, the increase in specific activity observed in catalysts RM089 and RM064 $(2,18,19)$ could be attributed to the fact that gold is partially covering the $\mathrm{MgO}$ surface, preventing to some extent the activity-suppressing interaction between ruthenium and $\mathrm{MgO}$.

The last sample of the $\mathrm{MgO}$ series, RM010, appears to be different in terms of morphology, microstructure, and catalytic activity. Electron microscopy indicates that all the $\mathrm{Ru}$ is located in small $(<4 \mathrm{~nm})$ particles, while $\mathrm{Au}$ is found in small, medium, and large particles. In this respect, catalyst RM010 resembles the $\mathrm{SiO}_{2}$-supported analog RS014. However, the stepwise chemisorption results point toward an important difference between these two catalysts. In the $\mathrm{SiO}_{2}$-supported

TABLE 2

Summary of Stepwise Chemisorption and Titration Results

\begin{tabular}{|c|c|c|c|c|c|c|c|c|c|c|}
\hline \multirow[t]{2}{*}{ Sample } & \multicolumn{3}{|c|}{$\mathrm{H}_{2}(293 \mathrm{~K})$} & \multicolumn{3}{|c|}{$\mathrm{O}_{2}(293 \mathrm{~K})$} & \multirow{2}{*}{$\begin{array}{c}\mathrm{O}_{2}(473 \mathrm{~K}) \\
\left(\mathrm{cm}^{3} / \mathrm{g}\right)\end{array}$} & \multicolumn{3}{|c|}{$\mathrm{H}_{2} / \mathrm{O}_{2}(373 \mathrm{~K})$} \\
\hline & $\mathrm{cm}^{3} / \mathrm{g}$ & $\begin{array}{c}\% D \\
(\mathrm{Ru})\end{array}$ & $\begin{array}{c}d \\
(\mathrm{~nm})\end{array}$ & $\mathrm{cm}^{3} / \mathrm{g}$ & $\begin{array}{l}\% D \\
(\mathrm{Ru})\end{array}$ & $\begin{array}{c}d \\
(\mathrm{~nm})\end{array}$ & & $\mathrm{cm}^{3} / \mathrm{g}$ & $\begin{array}{l}\% D \\
(\mathrm{Au})\end{array}$ & $\underset{(\mathrm{nm})}{d}$ \\
\hline RM089 & 0.305 & 7.9 & 11.6 & 0.22 & 5.8 & 15.9 & 1.24 & 2.51 & 2.1 & 53.1 \\
\hline RM064 & 0.27 & 11.5 & 8.0 & 0.295 & 12.6 & 7.3 & 1.34 & 2.70 & 3.16 & 35.2 \\
\hline RM010 & 0.042 & 14.6 & 6.3 & 0.064 & 11.1 & 8.3 & 0.215 & 0.36 & 3.2 & 35.0 \\
\hline
\end{tabular}


catalyst RS014, the nominal Au particle size derived from chemisorption is significantly smaller than the Au particle size obtained from WAXS (1) and the highly dispersed $\mathrm{Au}$ on the surface of the small particles is accessible to oxygen. However, on catalyst RM010 the particle size derived from chemisorption for both metals is larger than the WAXS particle size (Table 2) suggesting a certain loss of chemisorption capability of the small particles. Several scenarios could be envisioned to explain this decrease in gas uptake. First, there could be a lack of the right Ru and Au ensemble sizes required for $\mathrm{H}_{2}$ and $\mathrm{O}_{2}$ chemisorption. This is quite unlikely since a minimum of only two Ru surface sites are needed for $\mathrm{H}_{2}$ chemisorption, and since four $\mathrm{Au}$ surface sites are sufficient for $\mathrm{O}_{2}$ chemisorption at $473 \mathrm{~K}$. Second, the adsorption characteristics of the two metals could be altered due to electronic interactions between the two metals. However, the evidence accumulated so far on the RuAu system $(1-3,6,18,19)$ does not suggest a significant role of electronic interactions between $\mathrm{Ru}$ and Au. Finally, the low gas uptake on RM010 could be a manifestation of support effects. In this context, it is important to realize that the BET surface area and morphology of $\mathrm{MgO}$ supports can undergo drastic changes depending on the thermal history and the amount of impurities present $(20,21)$. During catalyst preparation by impregnation with aqueous metal salt solutions, $\mathrm{MgO}$ can undergo bulk hydration to $\mathrm{Mg}(\mathrm{OH})_{2}$. During pretreatment and reduction, the hexagonal close-packed hydroxide structure converts back to the simple cubic oxide involving a cooperative movement of $\mathrm{Mg}^{2+}$ and $\mathrm{O}^{2-}$ ions. An encapsulation of some of the metal particles during this restructuring event of the $\mathrm{MgO}$ is a strong possibility and the subject of further investigation in our laboratory. The comparison of the $\mathrm{SiO}_{2}$ series (1) with the $\mathrm{MgO}$ series demonstrates that the stepwise chemisorption procedure in conjunction with WAXS and electron microscopy can bring significant insight into the details of the microstructure of supported $\mathrm{Ru}-\mathrm{Au}$ catalysts. Such information is invaluable to understand the intricacies of catalytic activities and selectivities of such complex, bimetallic systems.

\section{ACKNOWLEDGMENTS}

This research was supported by the National Science Foundation through Grant CPE 8212473. Contributions to catalyst characterization by Dr. A. K. Datye, Mr. Jim Y. Lee, Dr. S. Galvagno, and Dr. G. R. Tauszik are gratefully acknowledged.

\section{REFERENCES}

1. Shastri, A. G., and Schwank, J., J. Catal. 95, 271 (1985).

2. Datye, A. K., and Schwank, J., "Proceedings, 8th International Congress on Catalysis, Berlin," Vol. IV, p. 587. Verlag Chemie, Weinheim, 1984.

3. Datye, A. K., Ph.D. thesis. The University of Michigan, 1984.

4. Tauszik, G. R., Leofanti, G., and Galvagno, S., J. Mol. Catal. 25, 357 (1984).

5. Bassi, I. W., Garbassi, F., Vlaic, G., Marzi, A., Tauszik, G. R., Cocco, G., Galvagno, S., and Parravano, G., J. Catal. 64, 405 (1980).

6. Schwank, J., Parravano, G., and Gruber, H. L., J. Catal. 61, 19 (1980).

7. Galvagno, S., Schwank, J., and Parravano, G., J. Catal. 61, 223 (1980).

8. Taylor, K. C., J. Catal. 38, 299 (1975).

9. Kubicka, H., React. Kinet. Catal. Lett. 5, 223 (1976).

10. Kubicka, H., J. Catal. 12, 233 (1968).

11. Goodwin, J. G., Jr., J. Catal. 68, 227 (1981).

12. Dalla Betta, R. A., Piken, A. G., and Shelef, M., J. Catal. 35, 54 (1974).

13. Sinfelt, J. H., and Yates, D. J. C., J. Catal. 8, 82 (1967).

14. Dalla Betta, R. A., J. Catal. 34, 57 (1974).

15. Vannice, M. A., J. Catal. 37, 449 (1975).

16. Kempling, J. C., and Anderson, R. B., Ind. Eng. Chem. Process Des. Dev. 9, 116 (1970).

17. Buyanova, N. E., Karnauklov, O. N., Koroleva, N. G., Ratner, I. D., Chernyavskaya, O. N., Kinet. Katal. 13, 1364 (1972).

18. Galvagno, S., Schwank, J., Parravano, G., Garbassi, F., Marzi, A., and Tauszik, G. R., J. Catal. 69, 283 (1981).

19. Datye, A. K., and Schwank, J., J. Catal. 93, 256 (1985).

20. Leofanti, G., Solari, M., Tauszik, G. R., Garbassi, F., Galvagno, S., and Schwank, J., Appl. Catal. 3, 131 (1982). 
21. Shastri, A. G., Chae, H. B., Bretz, M., and Department of Chemical Engineering Schwank, J., J. Phys. Chem., in press. The University of Michigan Ann Arbor, Michigan 48109

A. G. Shastri

J. SchWANK

Received October 10, 1984 